\title{
Compassion in Medicine
}

Every six months we get the most intelligent crop of junior doctors from across the country. They come from every corner of the country focused to work here and try to do their best. They will over the next few years work in a premier institute of India and will be mentored by probably the most experienced faculty in their respective fields. In terms of variety of diseases and experience this is a gold mine. But, when they leave from here, are we justified in making them a full humane doctor? Can Compassion and Competence go hand in hand? Can we teach them both or it is not possible.

The burning question behind all this is that "Can treating patients with medicine and compassion make a measurable difference on the wellbeing of both patients and doctors?" This very question was researched in detail by Trzeciak and Mazzarelli in their new book Compassionomics: The Revolutionary Scientific Evidence that

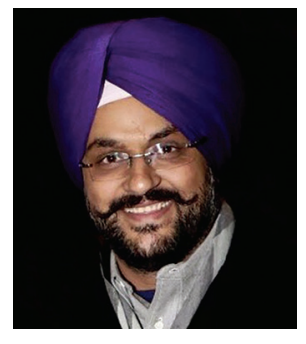
Caring Makes a Difference. After considering more than 1,000 scientific abstracts and 250 research papers, Trzeciak and Mazzarelli were surprised to find that the answer was, resoundingly, yes.

By researching further it was found that, there are two type of doctors who fit the profile:

- Empathetic doctors: those who naturally grasp that the whole point of empathy is to focus attention on the patient.

- Doctors who have successfully attended a doctor-patient communication skills course. (Communication skills can be taught).

For example, a good technique for showing compassion, is simple: 3 Ts. Talk or listen, take time and touch. Merely taking the time to talk and listen to patients is comforting, as is a doctor's touch. In the OPDs, wards and emergency settings the residents are working at $300 \%$ capacity and burnout is a reality. Burnout during residency training has gained significant attention secondary to concerns regarding job performance and patient care. Somewhere down the line of treating patients as humans and not as a diagnosis is need of the hour. Compassionate patient care has been associated with improved clinical outcomes for patients.

One study shows that when patients received a message of empathy, kindness and support that lasted just 40 seconds their anxiety was measurably reduced. There can be various ways of teaching compassion and clinical empathy to the residents. Good mentorship, role model and team spirit are some ways we can inculcate these qualities. The department of orthopedics has started a mentorship program in which each faculty mentors around 6-7 residents through their residency. As a surgeon, we are all aware of the God complex and how it can sometimes affect us; therefore, we need to be a team leader, be kind to the nursing staff, talk to the families of the patients pre-and postoperatively because we being compassionate will pay forward and give us a "Helpers high" as well as to the team. Even during OPDs showing more patience and hearing out the patients problems make us calmer and a better clinician and sets a good example for the residents.

In PGIMER, the workload and pressure is never going to lessen or get easier; so what we require is a curriculum and methods for physician and compassion training so that in all the chaos around us, we would still be able to show some compassion and understand as well as remember why we became a clinician in the first place. As Hippocrates said "Wherever the art of Medicine is loved, there is also a love of Humanity."

Sarvdeep Singh Dhatt

Additional Professor of Orthopedic Surgery

Postgraduate Institute of Medical Education and Research

Chandigarh, India 